\title{
ON THE UNDERLYING REPRESENTATION OF CONTOUR TONES IN WOBE
}

\author{
John Victor Singler \\ UCLA and NYU
}

\begin{abstract}
In a 1980 article entitled "The tone puzzle of Wobe," Thomas Bearth and Christa Link argue that only by positing phonemic contour tones can one account satisfactorily for the tone facts of Wobe, a western Kru language spoken in the Ivory Coast. In their analysis, they posit the features [Rise], [Fall], and [Concave] in addition to [High], [Low], and [Extreme]. In that their analysis abandons the assertion that surface glides can always be "de-composed" into sequences of underlying level tones, it represents an enrichment of phonological theory. The present account calls into question that enrichment, arguing not only that Bearth and Link's analysis obscures more insights than it captures but also that an analysis that uses only level tones at the phonemic level succeeds where Bearth and Link's account fails.
\end{abstract}

\section{Introduction}

Wobe is a western Kru language spoken in the western Ivory Coast. ${ }^{1}$ It is part of what Marchese [1979] terms "le conglomérat krahn-guéré-wobé,...une série de dialectes qui appartiennent en fait à une seule langue." (p. 13) In their 1980 account of Wobe tone, Bearth and Link (henceforth B\&L) argue for the existence of underlying contours. They use the features [Concave], [Fa11], and [Rise] in addition to [High], [Low], and [Extreme], and they posit fourteen tonemes.

The following is B\&L's feature chart (p. 182): ${ }^{2}$

'Will Leben's contributions are central to this paper. Independently, he and I had arrived at similar analyses of the Wobe data. What appears here is fundamentally a synthesis of those analyses. I am very grateful to him for all his help. At the same time, the responsibility for any errors is mine. I am also grateful to Bruce Hayes and Ian Maddieson for their suggestions.

${ }^{2}$ With six features, sixty-four tone combinations ought to be possible: $B \& L$ only posit fourteen. One might expect that the compensation (and justifi- 


$\begin{array}{ccccccc} & \text { High } & \text { Extreme } & \text { Low } & \text { Concave } & \text { Fall } & \text { Rise } \\ 1 & + & + & - & - & - & + \\ 2 & + & - & - & - & - & - \\ 3 & - & - & - & - & - & - \\ 4 & - & - & + & + & - & - \\ 31 & + & + & - & + & - & + \\ 32 & + & - & - & + & - & + \\ 41 & + & + & + & - & - & + \\ 42 & + & - & + & - & - & + \\ 43 & - & - & + & - & - & + \\ 15 & + & + & - & - & + & - \\ 25 & + & - & - & - & + & - \\ 35 & - & - & - & - & + & - \\ 45 & - & + & + & - & + & - \\ 435 & - & - & + & - & + & +\end{array}$

Their system has several curious features. Tone /4/, for example, is [+ Concave] yet is both [- Rise] and [-Fall]. The only [+ Extreme] tones are ones with a " $1 "$ constituent $(/ 1,31,41,15 /)$ and /45/. Some of the tones $(/ 41 /$ and $/ 42 /)$ are [+High] and [+ Low]. Implicit in an acceptance of the possibility that tonemes can be simultaneously [+ High] and [+ Low] is the abandonment of the universal definition of [High] and [Low]. That is, [High] and [Low] in Wobe (at least in B\&L's analysis of Wobe) do not mean what they mean elsewhere. This is underlined by the fact that the feature value [+ High] can refer to either endpoint of a contour, but [+ Low] refers only to the beginning. Moreover, it appears to be the case that in B\&L's analysis a toneme extends across a morpheme unless the toneme is $[+\mathrm{High}]$ or $/ 43 /$.

This paper will argue that a straightforward four-level-tone analysis of Wobe obviates the ad hoc devices of B\&L's account. This is not to say that the tone system of Wobe is free of idiosyncrasies. There are aspects of the Wobe

cation) for an inefficient system like this would be its ability to make neat descriptive statements. In fact, that is not what obtains. 
tone picture that appear to defy neat characterization. Nonetheless, overall, the Wobe system is one that lends itself nicely to a relatively "traditional" account.

The analysis proposed here uses an autosegmental framework, but the analytical framework is secondary. What is crucial is that contour tones are held to be underlyingly decomposable into sequences of level tones. ${ }^{3}$ (Because the single most important aspect of this analysis is the claim that surface glides are underlyingly sequences of level tones, the analysis will be referred to as the "compositional" analysis.)

The discussion is divided into three sections: the first discusses and reanalyzes falling tones and B\&L's /4/ and /42/ tonemes; the second discusses rising tones; the third presents an alternative account to what B\&L call compound-lowering. A four-level tone system is used, the features [High] and [Extreme] being employed in the following way: ${ }^{4}$

${ }^{3}$ Another Kru language, Klao, has also been analyzed as having underlying contour tones. Elimelech [1974] argues that Klao (which he calls "Kru") has two contour tones and two level tones underlyingly. However, acoustical measurement of the speech of Elimelech's informant failed to confirm the phonetic data on which his analysis is based [Jean-Marie Hombert, p.c.]. Light foot [1974] is able to account for the facts of $\mathrm{Klao}$ without positing underlying contour tones; rather, she posits three underlying level tones. According to Lightfoot (who also calls the language "Kru"), there is frequently a disparity between the underlying and surface tonal representations of forms, but she motivates melody-simplification and tone-spreading rules to account for this.

${ }^{4}$ While the term [Extreme] comes from Maddieson [1970], neither this use of the feature nor B\&L's conforms to Maddieson's use of it. Using the term as Maddieson intended it would yield, in the Wobe case, the following system:

$\begin{array}{cccc} & \text { [High] } & \text { [Low] } & \text { [Extreme] } \\ 1 & + & - & - \\ 2 & - & - & - \\ 3 & - & + & - \\ 4 & - & + & +\end{array}$

In the compound-lowering discussed in section 4, there is something of a tendency for tones $/ 1,2,3 /$ to group together to the exclusion of /4/. Thus, a case could be made for a system that uses the feature values proposed by Maddieson, particularly in light of [Maddieson 1971], where he discusses his tone features (including [Extreme]) from the perspective of markedness. Yip [1980] argues for the following feature system for Chinese: 


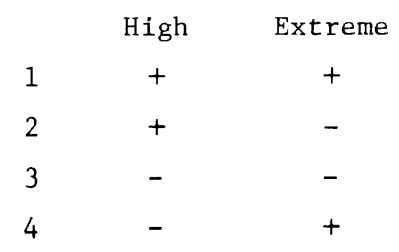

\section{Falling Tones and /4/}

In this first section, the focus will be on morphemes of the form $\mathrm{CV}$, but the conclusions drawn will extend to morphemes of all shapes.

The only time that $B \& L$ use " 5 " is as the endpoint of a falling tone. They observe that a contrast exists in their system between $/ 45 /$ and $/ 4 /$. Converting $5^{\prime} \mathrm{s}$ to $4^{\prime} \mathrm{s}$ in their formalism would obscure the contrast between these two. What B\&L label /4/ is level prepausally but ends in a rise elsewhere; also, what they label as $/ 45 /$ falls prepausally but is level elsewhere. B\&L describe these tones, i.e. assign underlying pitch designations to them, on the basis of their behavior prepausally. It will be argued here that it is their non-prepausal behavior that provides the key to their phonological identity. Thus, B\&L's $/ 4 /$ is $/ 42 /$ in the compositional analysis, i.e. not one toneme but two; their $/ 45 /$ is here $/ 4 /$ (and all other 5 's are converted to 4's ).

Evidence for this re-analysis comes from many sources. To begin with, it is common for a final $L$ to fall. Lavelle [1974], for example, describes its

\begin{tabular}{l|l} 
Register & $\begin{array}{l}\text { Tone } \\
+ \text { High } \\
\text { + Upper }\end{array}$ \\
\hline & + High \\
\hline - Upper & - High
\end{tabular}

Yip's treatment of tone is autosegmental, and she places Register and Tone on separate tiers. She marshals diachronic and synchronic evidence for her system. Wobe differs both in its history and in its present state from Chinese in ways that seem to preclude adaptation of Yip's system to Wobe. For example, one of the advantages of Yip's system for Chinese is that it captures limitations on possible contours. However, B\&L report six rising contours in Wobe; that is, all the rising contours that can occur in Wobe do occur. 
occurrence in certain situations in Yoruba. The other falls (B\&L's /15, 25, 35 , and 435/ ) have an endpoint that is "lower than 4" but, again, only in prepausal position. ${ }^{5}$ What this suggests is that the low-level phonetic rule that causes 4 to be realized as a low fall prepausally applies to every 4 , not just to cases where 4 is the only tone for the morpheme.

The compositional analysis claims that all of B\&L's final 5's are actually 4's, i.e. [- $\left[\begin{array}{l}-\mathrm{HI} \\ +\mathrm{EXT}\end{array}\right]$. This may seem to create a sort of musical chairs effect, but it will be shown that this is not a true problem. That is, if, as proposed, B\&L's /45/ is rewritten as $/ 4 /$ and their $/ 4 /$ is rewritten as 142/, what happens to their /42/? In fact, in their extensive list of tone contrasts on short monosyllabic morphemes, B\&L are unable to provide a monomorphemic example of the toneme they identify as /42/. Their examples of it are always morphologically complex. This is, it is argued, not accidental; it is, instead, a consequence of the fact that what B\&L call /4/ is actually $142 /$; thus, the $/ 42 /$ slot is already taken. (The compositional analysis's /42/, i.e. B\&L's /4/, is realized with a rise non-prepausally. Application of a rule of rise truncation prevents the $/ 2 /$ in the $/ 42 /$ from being realized prepausally. ${ }^{6}$ )

Evidence from Wobe verbs and verb suffixes provides further support for the analysis offered here. To begin with, a verb paradigm provides evidence specifically for the "de-composability" of what is here called the $/ 42 /$ melody. There are seven possible tonal melodies for verb roots:

5"In non-final position, the falling glide disappears, except for tone 25" (B\&L, p. 166).

${ }^{6}$ B\&L present fifty mingograms as an appendix to their article. It is not clear from them whether a rule of prepausal rise-truncation would have greater generality than /42/ melodies. There is, to be sure, a case to be made for similar rules of truncation in other western Kru languages, e.g. Kroumen (cf. Thalmann [1980]). As noted, B\&L present no monomorphemic examples of their proposed $/ 42 /$. The forms that they present with this melody are most often verbs to which the intransitivity suffix has been added. B\&L do not provide enough information to make it possible to determine what changes in the tonal melody occur when this suffix is added. They also do not illustrate by mingograms or discuss the phonetic differences between $p \tilde{J}^{4}$ (compositional analysis's $p \tilde{J}^{42}$ ) 'to look for' and $p \tilde{J}^{42}$ 'to look (intransitive)'. (Perhaps rise truncation applies only to morphologically non-complex /42/ forms.) 


$\begin{array}{cc}\text { Compositional } & \text { B\&L } \\ 1 & 1 \\ 2 & 2 \\ 3 & 3 \\ 43 & 43 \\ 42 & 4 \\ 41 & 41 \\ 34 & 35\end{array}$

The roots taken by themselves provide some small support for the compositional analysis (owing to the greater symmetry of $/ 43,42,41 /$ over B\&L's /43, 4, $41 /$ ). Much stronger support for it comes from a particular morphophonemic rule. After a falling-tone pronoun or a focussed subject, a $/ 4 /$ tone is affixed to the left of the verb. (If the verb root is underlyingly /4/-initial, then there is no change in the root's tone melody.) Thus, a $/ 1 /$ root is realized as /41/, a /3/ root as /43/. Crucially, a /2/ root is realized, following the prediction of the compositional analysis, as $/ 42 /$ (B\&L's/4/). ${ }^{7}$

Verb suffixes provide further evidence that bears on the competing ana1yses. In one case, it can be shown to support the compositional analysis; in another, the evidence is inconclusive. When a verb suffix (consisting of a vowe1) is attached, the final component of the tone melody of the root is copied, i.e. Wobe exhibits the type of evidence that Leben [1971] draws from Mende in support of the decomposability of contour tones. Thus, a /43/ root melody yields a [43-3] surface suffixed form, e.g.

$$
\text { te } \tilde{e}^{43} \text { 'buy' } \quad \tilde{e}^{43} \tilde{\varepsilon}^{3} \quad \text { 'buy + declarative' }
$$

The compositional analysis predicts that its /4/ tone would yield a [4-4] melody. A [4-4] melody is, in fact, what obtains:

$$
\mathrm{kwle} e^{4} \text { 'stay' } \mathrm{kwle} e^{4} \varepsilon^{4} \quad \text { 'stay + declarative' }
$$

In B\&L's analysis, the suffixed form of $/ \mathrm{kw}^{\mathrm{e}} \mathrm{e}^{4} /$ is $\left[\mathrm{kw} / \mathrm{e}^{45} \varepsilon^{45}\right]$. Since they acknowledge the rule to be one of copying of the final tone ("the ending

\footnotetext{
${ }^{7}$ As a consequence of this rule, a $/ 34 /$ root is realized as [4] ; some
} 143/ roots are realized as [4] while others are realized as [43] . 
point") of the root, forms like this one are exceptional for them, but not for the compositional analysis.

Assuming the regularity of the copying rule, the compositional analysis predicts that when a verb root has the melody $/ 42 /$, the suffixed form will be realized with a [42-2] melody. Inasmuch as in the B\&L analysis the same root is posited as being $/ 4 /$, the prediction that their analysis makes is that the suffixed form would have the melody [4-4]. In fact, they report that the copied tone is a [3]. The evidence in this case, then, supports neither the compositional analysis nor $B \& L ' s{ }^{8}$

Compound-lowering, presented fully in $\$ 4$; poses a problem for the compositional analysis. This process in part requires that, if the final constituent is a short monosyllabic morpheme that begins with a $/ 4 /$, the balance of that constituent's melody is lost, e.g.

$$
\begin{aligned}
& \text { pli } \tau^{41} \text { 'porcupine' } \quad \mathrm{kwla} \mathrm{a}^{2} \mathrm{pl}^{4} \quad \text { 'bush porcupine' } \\
& \mathrm{gbe}^{43} \text { 'dog' } \mathrm{kw} / \mathrm{o}^{4} \mathrm{gbe}^{4} \text { 'village dog' }
\end{aligned}
$$

This rule should therefore apply to /42/. B\&L present only one example of

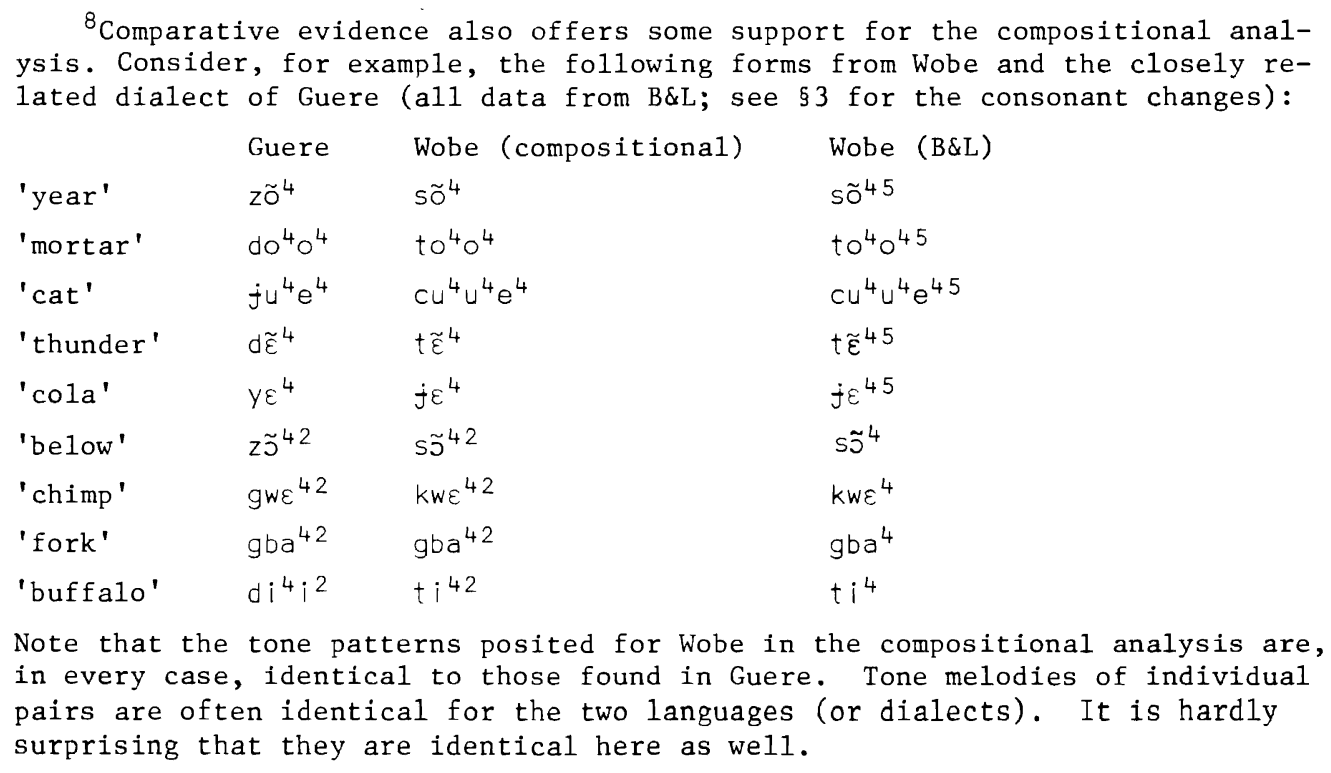


this, and it fails to undergo the rule:

$\begin{array}{lll}\text { Compositional } & B \& L & \\ \operatorname{sro}^{42} & s r O^{4} & \text { 'pile' } \\ k w \tilde{\varepsilon} \widetilde{\varepsilon}^{34} \mathrm{sro}^{42} & k w \tilde{\varepsilon}^{1} \tilde{\varepsilon}^{35} \mathrm{sro}^{4} & \text { 'pile of peanuts' } \\ {\left[{ }^{*} k w \tilde{\varepsilon}^{l} \widetilde{\varepsilon}^{34} \mathrm{sro}^{4}\right]} & \cdot & \end{array}$

In $B \& L ' s$ account, this form provides neither evidence nor counterevidence, but it is counterevidence to the compositional claim that $142 /$ parallels $141 /$ and $/ 43 / .9$ In longer words, on the other hand, there is no evidence of exceptional behavior for $/ 42 /$ forms.

The compound-lowering process has other exceptions to it. In the compositional analysis, the failure of short monosyllabic $/ 42 /$ forms to undergo it counts as an added exception. While this fact may be adduced as evidence against the compositional analysis proposed here, the force of all the evidence, when taken together, remains clear: there is no justification for invoking a fifth tone that is "extra-low". Falling tones can be characterized as being decomposable with $/ 4 /$ as their final constituent. B\&L's $/ 45 /$ can be rewritten as /4/, their /4/, which they acknowledge as being rising everywhere except prepausally, as /42/.

\section{Rising Tones}

The only difference between B\&L's analysis and the one proposed here in the assignment of underlying melodies involves those discussed above. Melodies cited subsequently will be those of the compositional analysis except where noted. Thus, for example, when $/ 4 /$ is referred to, it is the compositional /4/, not the B\&L /4/.

In a four-tone system, six rises are possible: $21,31,32,41,42,43$. The $/ 21 /$ melody is associated with $\mathrm{CV}_{2}$ forms but not with $\mathrm{CV}$ forms. Apart from that, there are no restrictions on distribution.

${ }^{9}$ That $/ 42 /$ here behaves differently from $/ 41 /$ and $/ 43 /$ and that a non-prepausal /24/ behaves differently from $/ 14 /$ and $/ 34 /$ when they occur in the same position (cf. fn. 5) would provide a bit of support for a feature system along the lines proposed by Yip in that such a system would group together 1 and 3 to the exclusion of 2 . 
In $\mathrm{CV}_{2}$ forms the relationship of vowel to tone follows from the Well-Formedness Condition as set out in Goldsmith [1976] and from a straightforward mapping, starting from the left, of one tone to one vowel in all cases when the first tone is a $/ 2 /$ or a $/ 3 /$ and in some-but not all-cases when it is a $/ 4 /$, e.g.

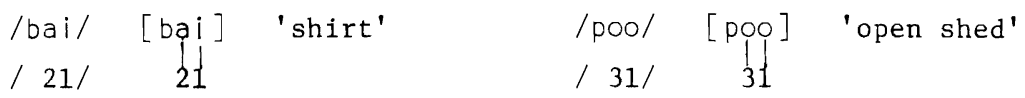

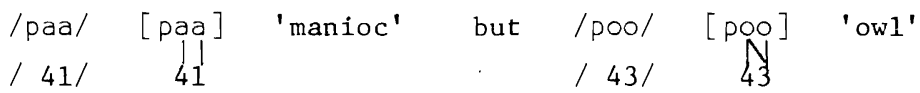

The following discussion presents a historical account (drawn from B\&L) of how exceptional forms entered the language and then proposes a language-specific adjustment of the mapping principles.

In Krahn and Guere, parts of "le conglomérat krahn-guéré-wobé", and in the related languages Bassa and Dewoin, links have been noted between consonant type and tone (see Tisher [1979] for Krahn, B\&L for Guere, Hobley [1964] for Bassa, and Welmers [1975] for Dewoin). In general, the consonant inventories can be divided into voiceless, voiced, and implosive. Note that while the implosive consonants are voiced as well, the term "voiced consonant" here refers to non-implosive consonants only. Though there are exceptions, the usual pattern is that a voiced consonant in these languages lowers the onset of the following tone. In the case of Wobe, this is no longer true. B\&L make a strong case for a scenario in which the following has happened in Wobe:
a. the phonetic process that lowers the onset of a tone following a voiced consonant became phonologized;
b. voiced consonants became voiceless, e.g., Proto Guere-Wobe $/{ }^{*} d v^{\mathrm{T}} /$ became $/ \mathrm{tV}^{4 \mathrm{~T}} /$ (where $\mathrm{T}$ represents any tone) as a consequence of the steps outlined in (a) and (b);
c. implosive consonants became voiced (non-implosive) consonants.

As $B \& L$ note, there are some exceptions to their generalization: /gb/, for example, seems not to have become $/ \mathrm{kp} /$ (there are no $/ \mathrm{kpV}^{4(\mathrm{~T})} /$ words in contemporary Wobe).

Given this scenario, it is those forms that have undergone the shifts de- 
scribed in (a) and (b) and that have the shape $\mathrm{CV}_{2}$ that violate the principle of one-to-one mapping of tone to vowel:

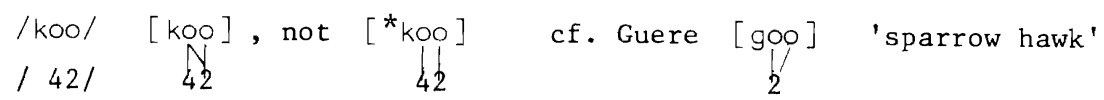

In order to accommodate forms of this sort in the present analysis, two steps must be taken. The first is to associate lexically the $/ 4 /$ tone to the first vowel of the form, e.g.

$$
\begin{array}{ll}
/ \text { koo/ 'sparrow hawk' } & / \text { kwę/ 'canoe' } \\
/ 42 / & / 41 /
\end{array}
$$

(Apparently, the only $\mathrm{CV}_{2}$ forms that violate a straightforward one-to-one mapping are the ones that have undergone the shift. It is only these forms that get lexical associations. ${ }^{10}$ ) The second step is to set up mapping principles of the following sort: ${ }^{11}$

10 Because $\mathrm{CV}$ forms that have undergone the shift historically do not create any problem for a one-to-one mapping procedure, they have not been assigned lexical associations. Were they assigned them, no change would obtain on the surface, so the question is not a critical one. The use of lexical associations, proposed in Leben [1978] and argued against in Singler [1980], can be avoided in Wobe if a diacritic, [+ Low Tone], is attached to the consonant responsible for the introduction of the initial low tone. Then, after tonemapping, a rule would convert $\underset{[+\mathrm{LT}]}{\mathrm{C}} \mathrm{V} \mathrm{T}$ to $\mathrm{C}_{\mathrm{T}}^{\mathrm{V}}$. Employing this solution renders unnecessary any special association convention. I leave in abeyance the question of whether the use of a diacritic is preferable to the use of lexical associations.

${ }^{11}$ The mapping principle and the Well-Formedness Condition are sufficient to yield most of the surface forms. In the case of some $\mathrm{CV}_{2}$ forms ending with a falling contour, however, an added rule of tone spread is needed:

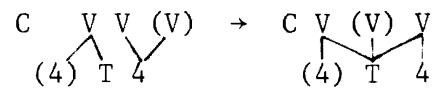

This rule is a late rule, applying after the compound-lowering rules described in $\$ 4$. For some falling contours, B\&L posit an intervening tone, e.g. $1134 /$ ( $/ 135 /$ in their terms). The mingograms presented as an appendix to their article fail to demonstrate conclusively the presence of such a tone. B\&L present no mingograms of what they label C $\mathrm{X}$. comments about them are possible. 
a. Associate the first unassociated tone with the first syllable, the second with the second, and so on, until all tones or syllables are exhausted.

b. Tones or syllables not associated as a result of (a) are subject to the Well-Formedness Condition.

Some illustrations of the mapping principles are the following:

(a)

$\begin{array}{lc}/ \mathrm{kaO} / & \rightarrow \\ / 42 / & {[\mathrm{kao}]} \\ 42\end{array} \quad$ 'palm tree'

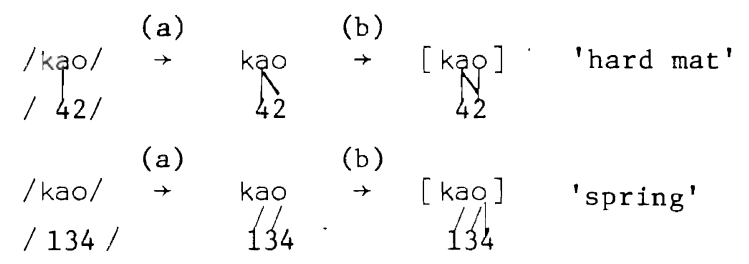

4. Compound-Lowering

One of B\&L's claims is that the feature system they devised is better able to account for compound-lowering in Wobe. It will be a fair test of the analysis proposed here to see if it can succeed in capturing the basis of compoundlowering more directly and more succinctly, even though $B \& L$ apparently created theirs to address this particular set of facts. In Wobe compound-lowering, a single underlying tendency effects various changes in surface forms, although the surface manifestations of compound-lowering defy simple characterization. Still, it is a compositional analysis that seems best able to capture the available generalizations.

"Compound-lowering" is the set of phonological operations by which the tone melody of part or all of the final constituent of a compound is lowered. There are two types of lowering: one affects only the tones of the first vowel of the constituent (assuming that the mapping of tones to vowels has already occurred before compound-lowering applies).

With regard to the first vowel, compound-lowering accomplishes the following :

a. It lowers the level tone or the first part of a falling tone to a 3 , e.g. 


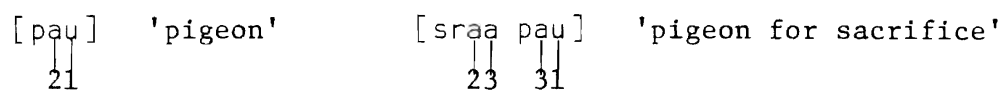

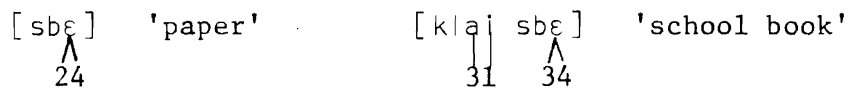

b. A tone that undergoes the lowering described in (a) is lowered still further when a 4 is the tone of the final vowel of the previous constituent, e.g.

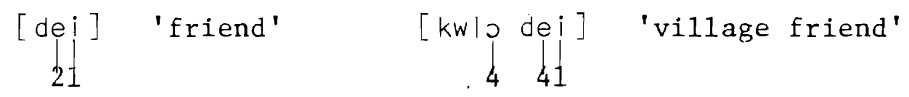

c. When the first vowel of the final constituent has the tone pattern [4T], the pattern is changed to [4], e.g.

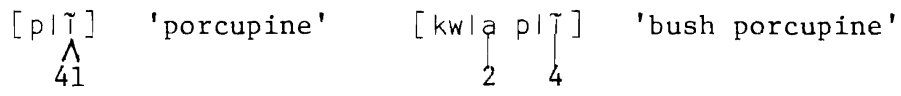

The rules that bring about these changes are RULES $1 \mathrm{a}-\mathrm{c}$ below respective1y. In every case, the $V$ in question is the first vowel of the final constituent of a compound.

RULE 1a

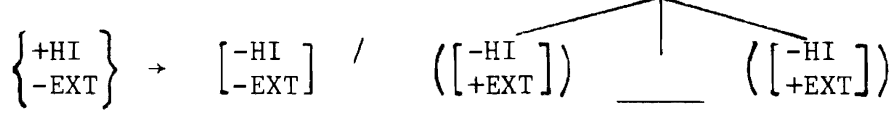

RULE 1b

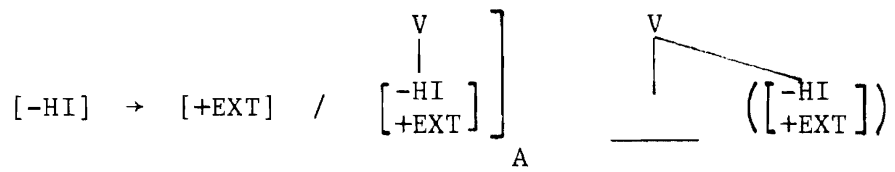

RULE 1c

$$
[-\mathrm{HI}] \rightarrow[+\mathrm{EXT}] /\left[\begin{array}{l}
-\mathrm{HI} \\
+\mathrm{EXT}
\end{array}\right] \rightarrow\left(\left[\begin{array}{l}
-\mathrm{HI} \\
+\mathrm{EXT}
\end{array}\right]\right)
$$

The $A$ in the structural description of RULE $1 \mathrm{~b}$ refers to the preceding constituent of the compound.

Because the three rules are all manifestations of a single phenomenon and because their structural descriptions largely overlap, it is appropriate to collapse them into a single rule. 
RULE $1^{12}$

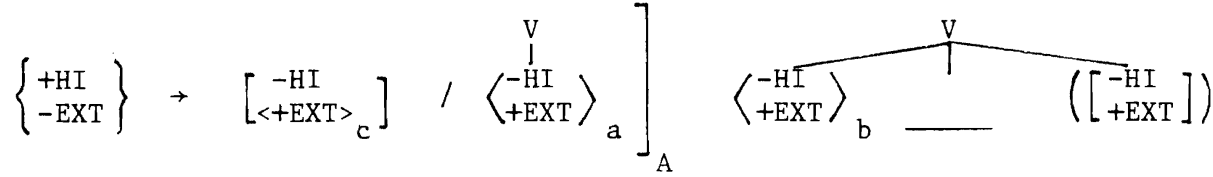

$$
\begin{aligned}
& \text { Condition: if a or b, then } c \text {. }
\end{aligned}
$$

As has been noted, the changes accomplished by this rule affect only the initial vowel of the final constituent of a compound. In addition, two very simple rules affect the melody of the entire constituent. These must be ordered to follow RULE 1 . The first changes a level 3 melody to a fall:

RULE 2

$$
\left.\emptyset \rightarrow 4 /]_{A} 3-\right]_{B}
$$

( $A$ and $B$ refer to elements of a compound.)

The following examples illustrate the operation of these rules:

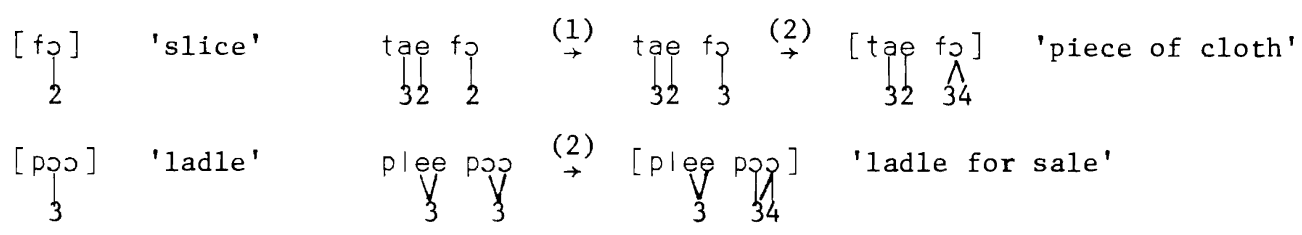

The second rule that affects the entire melody of the final constituent flattens out contours, removing all non- 4 tones when the first and last tones are 4 's:

${ }^{12}$ Using the feature values proposed by Maddieson [1970, 1971] and discussed in fn. 4 would simplify the rule somewhat. That is, when $/ 4 /$ is the sole [+Extreme] segment, RULE 1 can be restated thus:

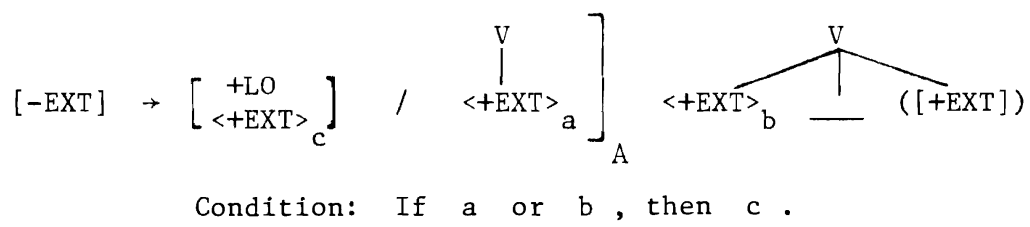


RULE 3

$$
\left.\left.\mathrm{T}_{1} \rightarrow \varnothing /\right]_{\mathrm{A}} 4-4\right]_{\mathrm{B}}
$$

RULE 3 is illustrated in the following example:

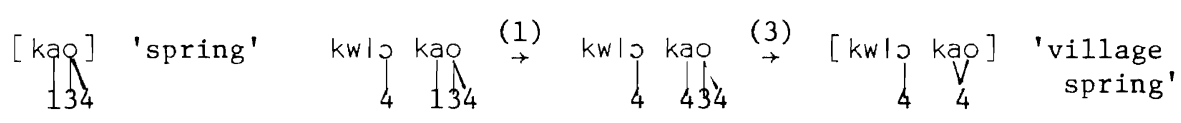

Compound-lowering does not apply to every form in the language. RULE 1's structural description excludes forms that begin with

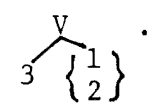

In a few cases, it is necessary to mark forms lexically as being exceptions to a rule. RULE 1 does not apply to a final constituent having the underlying form /CVV/, but it does affect one with the underlying form /CVV/ , e.g.13 / $31 /$

$$
\begin{aligned}
& \text { [dao] 'smoke' kw/q dao } \begin{array}{l}
(1) \\
3.2
\end{array} \\
& \text { [sij] 'grass' jesij (f) [jes sji] }
\end{aligned}
$$

Also, as noted at the end of $\$ 2$, a short monosyllabic form with the melody 142/ must be marked as an exception to RULE 1 . Longer words with this melody are not exceptional in their behavior, e.g.

$$
[\begin{array}{c}
\text { [toag } \\
42
\end{array} \text { [machete' [kwlo toao t } \underbrace{V}_{42}] \text { 'village machete' }
$$

${ }^{13}$ The same type of idiosyncratic behavior that characterizes $C$ V $\begin{aligned} & 1 \\ & 3\end{aligned}\left\{\begin{array}{l}1 \\ 2\end{array}\right\}$

forms with regard to compound-lowering may also characterize CVV forms whose second vowel is linked to a /3/. In particular, the forms [dog] 'elephant' and [poo] 'owl' present problems that can only be resolved by further investigation. In the first case, the situation is muddled by the possibility of a typographical error in B\&L, p. 174. 
Apart from these exceptions, the fact that $\bigwedge_{31}^{\mathrm{CV}}$ and $\bigwedge_{32}$ and $\mathrm{CVY}$ forms do not undergo any of the compound-lowering rules but CYY forms do illustrates the quirky distribution of compound-lowering. That is not, however, a fact about any particular analysis, but rather a fact about compound-lowering.

At any rate, the analysis presented here displays a simplicity lacking in $B \& L$ 's analysis, a fact immediately evident from comparison of their rules for compound-1owering with RULES 1-3 above. The feature values referred to are those in the chart given at the beginning of this article: $B \& L ' S \quad P_{1}$ :

$$
\left.\left.\left[\begin{array}{l}
\text {-Concave } \\
\alpha \text { Low }
\end{array}\right] \rightarrow\left[\begin{array}{l}
\text {-High } \\
\alpha \text { Low } \\
+ \text { Fal1 } \\
\text {-Rise }
\end{array}\right] /\right]_{A}+\mathrm{C}-(\mathrm{V})(\mathrm{V})\right]_{B}
$$

$B \& L$ 's $P_{2}$ :

$$
\left.\left[\begin{array}{l}
\text {-High } \\
\text {-Low } \\
+ \text { Fal1 } \\
\text {-Rise }
\end{array}\right] \rightarrow[\text { +Low }] /\left[\begin{array}{l}
\text { +Low } \\
+ \text { Fal1 } \\
- \text { Rise }
\end{array}\right]+\mathrm{C}-(\mathrm{V})(\mathrm{V})\right]_{B}
$$

$B \& L ' s \quad P_{3}$ :

$$
\left.\left\{\begin{array}{ll}
\text { a) } & {[+ \text { Fall }]} \\
\text { b) } & {[- \text { High }]} \\
\text { c) } & <+ \text { High }>
\end{array}\right\}+\left[\begin{array}{l}
\text {-High } \\
\alpha \text { Low } \\
+ \text { Fall } \\
- \text { Rise }
\end{array}\right],+C\left[\begin{array}{c}
\mathrm{V}^{2} \\
\text {-High } \\
\alpha \text { Low } \\
+ \text { Fall } \\
- \text { Rise }
\end{array}\right]-\left(\begin{array}{c}
\mathrm{V} \\
<+ \text { Fall }>
\end{array}\right)\right]_{B}
$$

5. Conclusions

Despite B\&L's claim that the complexities of Wobe tone require the introduction of underlying contour tones and the positing of fourteen tonemes, a compositional analysis can express the same facts-and can express them with greater simplicity and greater insight. In the compositional analysis presented here, non-prepausal (rather than prepausal) representations of tone patterns were held to be better indications of their underlying character. 
Though there is no reason to select the forms as they appear in one environment over the way they appear in another a priori, evidence from verbs, particularly verb roots, provided confirmation of the preferability of the compositional analysis.

Once the adjustment of these tone patterns was made, the particulars of a compositional account of Wobe were set out. Because of the historical effect of some "depressor" consonants, it was necessary to posit lexical associations for a particular type of form and to make a related adjustment in the mapping principle of first tone to first vowel (or, alternatively, to employ a diacritic rather than lexical associations). Once that was done, the only things needed to solve the tone puzzle of Wobe were four level tones, the Well-Formedness Condition, tone-mapping principles, and some unremarkable tone-spreading rules.

The compositional treatment of the morphophonemic process of "compoundlowering" provides an indication of the ability of such an analysis to account for the facts of Wobe. Thus, B\&L's arguments to the contrary, while the possibility remains that there are languages for which underlying contour tones must be posited, wobe is not such a language. 


\section{REFERENCES}

Bearth, Thomas and Christa Link. 1980. "The tone puzzle of Wobe." Studies in African Linguistics 11:147-207.

Elimelech, Baruch. 1974. "On the reality of underlying contour tones." In Ian Maddieson (ed.), The Tone Tome: Studies on Tone from the UCLA Tone Project, pp. 74-83. UCLA Working Papers in Phonetics, 27. Los Angeles: UCLA Department of Linguistics.

Goldsmith, John. 1976. "Autosegmental phonology." Ph.D. dissertation, MIT. [Published by Bloomington: Indiana University Linguistics Club.]

Hobley, June. 1964. "A preliminary tonal analysis of the Bassa language." Journal of West African Languages 1.2:51-5.

Lave1le, Car1. 1974. "An experimental study of Yoruba tone." In Ian Maddieson (ed.), The Tone Tome: Studies on Tone from the UCLA Tone Project, pp. 160-70. UCLA Working Papers in Phonetics, 27. Los Angeles: UCLA Department of Linguistics.

Leben, William R. 1971. "Suprasegmental and segmental representation of tone." In Talmy Givón (ed.), Papers from the Second Conference on African Linguistics, pp. 183-200. Studies in African Linguistics, Supplement 2 .

Leben, William R. 1978. "The representation of tone." In Victoria Fromkin (ed.), Tone: A Linguistic Survey, pp. 177-219. New York: Academic Press.

Lightfoot, Nancy. 1974. "Tones on Kru monosyllables." Anthropological Linguistics $16: 425-41$.

Maddieson, Ian. 1970. "The inventory of features required for handling tone in transformational phonology." Ian Maddieson (ed.), Tone in Generative Phonology, pp. 3-21. University of Ibadan Research Notes 3, Parts 2 \& 3.

Maddieson, Ian. 1971. "Tone system typology and distinctive features." André Rigault and René Charbonneau (eds.), Proceedings of the Seventh International Congress of Phonetic Sciences, pp. 957-961. The Hague: Mouton.

Marchese, Lyne11. 1979. Atlas Iinguistique kru: Essai de typologie. Abidjan: Institut de Linguistique Appliquée.

Singler, John Victor. 1980. "The status of lexical associations and the Obligatory Contour Principle in the analysis of tone languages." Berkeley Linguistics Society 6:442-56.

Thalmann, Peter. 1980. Phonologie du Kroumen. Publications Conjointes ILA/SIL no. 5. Abidjan: University of Abidjan.

Tisher, Herb. 1979. "Tchien Krahn tone." Paper presented at the First International Symoosium on Kru Languages, Abidjan.

Welmers, William E. 1975. "Dèwว̄̄: Some notes and questions after two weeks." UCLA ms.

Yip, Moira. 1980. "The tonal phonology of Chinese." Ph.D. dissertation, MIT. [Published by Bloomington: Indiana University Linguistics Club.] 
